\title{
Sciendo
}

Ethics \& Bioethics (in Central Europe), 2018, 8 (1-2), 5-13

DOI:10.2478/ebce-2018-0004

\section{The golden rule of morality - an ethical paradox}

\author{
Tibor Máhrik ${ }^{1}$
}

\begin{abstract}
This paper focuses on the dynamics of ethical perspectives that embody the Golden Rule of Morality. Based on critical analysis of this rule in various cultural and religious contexts, but also from the perspective of humanism, the author presents its paradoxical character, the essence of which is interpreted here in terms of a pointer to metaphysical reality. It turns out that social conditionality, as well as the self-referential concept as a starting point of any ethical reasoning, are serious epistemological challenges for the application of the Golden Rule in the position of universal normativity that this study addresses. On the other hand, Judeo-Christian cosmology and the related basis for ethical foundations is presented here as an inspirational space of ethical reasoning in which the paradoxical character of the Golden Rule becomes rather an indicator of a deeper metaethical interpretation of one's own particular ethical attitudes and outcomes than a practical guide to the discovery of ethical universals.
\end{abstract}

Keywords: Golden Rule, humanism, Judaeo-Christian perspective, absolute values, ethical paradox, metaethics

\section{Introduction}

Current professional discussions but also those held on wider platforms in society which discuss general social issues are more and more devoted to the issue of morality, the question of ethical foundations, the challenge to seek solutions to ethical dilemmas in the light of moral philosophy. This has to do with politics but also the world of technology, business, team work, family life or, in fact, any other areas of man's research. The Golden Rule presents an important codification of the moral basis to create applied ethical frameworks which can be found across cultures. The study critically reflects this self-referential moral indicator from philosophical and theological points of view, which is presented as an indicator of meta-ethical realities in the context of current ethical research.

In general, the Golden Rule is known in its negative form and its positive form: One should not treat others in ways that one would not like to be treated oneself. One should treat others as one would like others to treat oneself. It symbolizes life in truth, righteousness, beauty and harmony. What is the intrinsic value of such a rule? What is its applicability in the social context? This utilitarian concept has some undeniable positives but also some limits. It is an understandable, simple and viable rule which, however, opens up an interesting logical circle: an inevitable predisposition of understanding of what needs to be done is derived from actions of other individuals with respect to the relevant individual, and the resulting consequential imperative determining the action of that individual towards the environment depends on the reflexive quality and power on the side of the acting individual. In making an ethical analysis of this rule, the key aspect is mainly consistency in the thinking and acting of the individual that reflects the dialectics of the relation "I - my surroundings" (Wattles, 1996, pp. 169-170). Because of its semantic structure, this seemingly simple principle of moral thinking overlaps, however, several issues in the field of philosophy, psychology and theology. This study discusses some of them in more detail.

\footnotetext{
${ }^{1}$ Constantine the Philosopher University in Nitra (Slovakia); email: tmahrik@ukf.sk
} 


\section{The paradoxical character}

Even though a number of special publications and studies rank the Golden Rule among those ethical rules based on the principle of reciprocity, we find this to be unjustified. On the contrary, we believe that it is necessary to point out an important fact, namely that in applying this rule, it does not concern the principle of anticipated reciprocity, according to which I would anticipate a similar "response" to my actions; it rather concerns a unilateral moral commitment on the part of the subject, a kind of attitude to society of which the subject is part, irrespective of the attitude and the moral practice of the social environment. As stated by Neusner and Chilton, if reciprocity would be foundational to the Golden Rule, then reciprocal obligations would be essentially ethical and social in their aim and reference; secondly, they would be independent of the desires, aims, and preferences of this or that particular individual; thirdly, they would be autonomous of the desires and feelings of the agent (Neusner \& Chilton, 2008, p. 11).

The reciprocal character of the Rule is only apparent. Closer examination shows that the semantic structure of the Rule builds on the anthropocentric concept, where the key role of a moral agent is played by man and man's feelings, preferences, and cultural and social background. These characteristics of the moral individual are not universal, but they are highly variable. Thus, the Rule presents a clear paradox. On the one hand, it is expected that the decision-making of the individual in his moral actions will be independent of the responses of the surroundings, and on the other hand, according to this Rule, moral decisionmaking is dependent on the assessment of its consequences and on the effect of surrounding behaviour towards the individual.

\section{The historical aspect}

In ancient Egyptian texts (approx. 2000 BCE), we can find some interesting inspiring modifications of the Golden Rule: "Is your master hateful? Reprove him! (But) an abomination is the reproving of him? Be silent! Do not reply! Do not praise until he recognizes the greatness/importance of that which you did for him. That which you hate to be done to you, do not do to another" (Jasnow, 1992, p. 95). The context of the Golden Rule results from the above text, and in this case, the context is given by the social inequality of individuals, in terms of power rather than in existential terms. It is interesting to note the condition "until he recognizes", which significantly shifts the semantic focus of the Golden Rule farther away from the deontological focus. Suffering and misunderstanding become an obstacle to the conduct which would otherwise be considered an ethical imperative. Personal calculation and benefit indirectly come to the fore.

The Chinese tradition knows the moral concept of reciprocity of Confucius (500 BCE): "Zi Gong asked, saying: Is there one word which may serve as a rule of practice for all one's life? The Master said: Isn't RECIPROCITY such a word? What you do not want done to you, do not do to others" (Legge, 2017). The foundation of the above principle is the social context and functioning of society as a whole. The reciprocity principle was supposed to ensure the stability of society, and the observance of the established rules without which no large social entity could function. In a complex social system, a violation of reciprocity results in social turbulence and the destabilization of the community. Therefore, reciprocity has its rationale in the consequential perception of ethics, but not in the deontological perception. This way of thinking, however, does not resolve the conflict that arises in the ethics of obligations - e.g. obligations towards parents, friends etc.

The ancient Hindu sage of Brihaspati (850-650 BCE) mentions the virtuous effort of man, which is accomplished by observing the dharma (the right conduct of one's own caste): 
"One should never do that to another which one regards as injurious to one's own self. This, in brief, is the rule of right conduct (dharma). By acting in a different way by yielding to desire, one becomes guilty of wrong conduct. In refusals and gifts, in happiness and misery, in the agreeable, and the disagreeable, one should judge their effects in reference to one's own self. When one injures another, the injured party turns round and injures the injurer. Similarly, when one cherishes another, that other cherishes the cherisher. One should frame one's rule of conduct according to this. I have told you what right conduct is even by this subtle way... By making dharma your main focus, treat others as you would treat yourself” (Ganguly, 2017).

The text analysis correlates with the karmic principle and the moral principle of equilibrium based on the presumption that it is possible to achieve moral equilibrium of acts which two individuals "exchange". From the perspective of the European tradition and the JudaeoChristian perception of the world, such a principle of equilibrium is untenable, as everybody is an original, and everybody is unique by its subjective specificity.

The ancient Persians knew various versions of this ethical principle, which they considered to be an expression of the naturalness of the world: "That nature alone is good which refrains from doing to another whatsoever is not good for itself" and similarly: "Whatever is disagreeable to you, do not do unto others" (Firminger, 2008, pp. 2526). They were based on the assumption of strict causal relationships that are inherent to the observed world of which man is a part. There is the question regarding man's freedom in forming his moral judgments and actions. In this respect, the ancient Persians' vision of the world was not consistent.

In formulating his numerous ethical principles, Buddha (623-543 BCE) built on the basic thesis of Buddhism - they are just like I am, I am just like they are. A relation to others is not determined by empathy which would consider the otherness of both involved entities. On the contrary, their sameness in terms of the internal nature of enlightenment is considered. This principle is evident from the Dhammapada text in Chapter 10 on violence (published by the Buddha Dharma Education Association \& BuddhaNet): "All tremble at violence; life is dear to all. Putting oneself in the place of another, one should not kill nor cause another to kill" or "One who, while himself seeking happiness, oppresses with violence other beings who also desire happiness, will not attain happiness hereafter. One, who, while himself seeking happiness, does not oppress with violence other beings who also desire happiness, will find happiness hereafter". It is important to know, that any Judeo-Christian ideas must not be put into these Buddhist expressions, as "of any immaterial existence Buddhism knows nothing" (Rhys-Davids, 1903, p. 132). Buddhism as a view of the world, society and the individual is based on a strictly self-referential concept of thinking. It means that the relation to oneself is the dominating principle for the definition of consequent relations to one's environment "The Golden Rule in Buddhism reads - one who loves himself should not harm another - as neither are completely positive or negative, but conditional and relative; moreover, it falls somewhere between a simple observation and a prescriptive command. If a person loves himself, he should not harm another because that would violate the integrity of the self of the other person" (Chilton \& Neusner, 2008, p. 117).

During his public life, Muhammad (570-632 CE) criticized the principle of blood vengeance, which was a generally accepted ethical principal at that time. The reason for its acceptance was the dominant principle of the clan's survival. But when the maintenance of the internal clan's dynamics was considered, Muhammad sought to maintain the cohesion and stability of the clan, community; therefore, he preferred the principle "do not hurt anybody so that nobody hurts you". Commentators and analysts of Muhammad's moral reasoning and ethical teaching agree that Qur'an 83:1-6 contains the Golden Rule in an implicit form, whereby its explicit formulations appear in various places in the traditional collections of his statements and written texts (Hadith) (Chilton \& Neusner, 2008, pp. 101- 
106). For example: "Pay, oh Children of Adam, as you would love to be repaid, and be just as you would love to have justice" (Chilton \& Neusner, 2008, p. 101). The righteous reciprocity rule is assumed in the relations between Muslims; however, it is not mentioned anywhere in respect of other social or religious entities - "There Muhammad said: None of you believes until he loves for his brother what he loves for himself" (Chilton \& Neusner, 2008, p. 102). The term brother is exclusive and includes those who comprise the community of Muslims. In making a detailed analysis of the texts, we will not miss the implicit fusion of terms such as faith, justice, love etc., by which the definition of the reciprocal ethical principle is exclusively bound to the community which has faith as a common denominator.

\section{The humanistic perspective}

The Golden Rule of morality has its counterparts in psychology, economics, environmental sciences as well as legal systems. The challenge to treat others as we would like to be treated by others is the basic ethical axis of humanist thinking. To place oneself in the place of others, to respect the value and coordinates of others, to tolerate the cultural context of others etc. has, therefore, naturally become the moral imperative of the educated, progressive and inclusively anchored man of the $21^{\text {st }}$ century. In general, it is true that "the Golden Rule is a concept that essentially no religion entirely lacks. But not a single one of these versions of the Golden Rule requires a God" (Epstein, 2010, p. 115). The application of the Golden Rule is not, in any way, conditioned by and bound to God in the Judaeo-Christian understanding. The current discourse on the fundamentals of ethics, however, raises questions that lead to the fact that an understanding of the Golden Rule of morality is anchored exclusively in the humanist foundations of understanding of any work; it is not as simple at all as it might seem at first sight. It collides with problems that cannot actually be solved from the perspective of humanism.

In his book Ethics: A Very Short Introduction, Blackburn makes an analysis of the development in ethical thinking of the western world in comparison with the major ethical systems of the world, and points out different approaches in thinking: "[A]n ethical climate is a different thing from a moralistic one. Indeed, one of the marks of an ethical climate may be hostility to moralizing, which is somehow out of place or bad form. Thinking that will itself be a something that affects the way we live our lives. So, for instance, one peculiarity of our present climate is that we care much more about our rights than about our good. For previous thinkers about ethics, such as those who wrote the Upanishads, or Confucius, or Plato, or the founders of the Christian tradition, the central concern was the state of one's soul, meaning some personal state of justice or harmony" (Blackburn, 2013, pp. 3-4). The tension between the ethical position of searching for inner harmony on the one hand and pressure from society on the other hand presents the inevitable reality whose dialectic is different in each culture and each society.

Some scholars believe that the Golden Rule can build a humanist society based upon compassion and mutual respect:

"[M]oral directives do not need to be complex or obscure to be worthwhile, and in fact, it is precisely this rule's simplicity which makes it great. It is easy to come up with, easy to understand, and easy to apply, and these three things are the hallmarks of a strong and healthy moral system. The idea behind it is readily graspable: before performing an action which might harm another person, try to imagine yourself in their position, and consider whether you would want to be the recipient of that action. If you would not want to be in such a position, the other person probably would not either, and so you should not do it. It is the basic and fundamental human trait of empathy, the ability to vicariously experience how another is feeling, that makes this possible, and it is the principle of empathy by which we should live our lives" (Lee \& Musings, 2013). 
It is a paradox that the very humanist scientific disciplines themselves question the fundamental assumptions of the argumentation advanced by Lee and Musings. To what extent is one able to put oneself into the inner world of others? Are we able, in any effort to do this, to take into account cultural, social and religious differences?

The anthropological question "Who is man?" remains the key question of the humanist perspective of thinking of the fundamentals of ethics (Tavilla, Kralik \& Martin, 2018, pp. 356-359). What powers emerge in his consciousness and unconsciousness, influencing the world of his motives and decision-making processes? From a philosophical point of view, in this discourse, the argument of Trasymachus is important, as it points out the polarity of man's hidden world with regard to his moral thinking. According to this argument, for example, "justice" is an issue of social convention rather than an issue of an objective aspect of justice as such. Since the laws of society are created by political entities that have social power and authority, justice does not have objective parameters. Instead, it only presents an image of the will of the most powerful political group and its interests. Given such a case, how can one justify moral categories as an objective fact? Plato's answer to Trasymachus is that the unjust man does not have happiness after all. This is so because it is more profitable to be just than unjust. Why is this so? A just soul is harmonious and happy, while an unjust soul is disharmonious and unhappy (Neusner \& Chilton, 2008, p. 23). Is it really true that a happy man is one who is just? Neither life practice nor the current research of cognitive sciences confirms this thesis. Plato's dualism of the pragmatic aspect of ethical frameworks and the harmony of man's soul is unsustainable in terms of what occupies current researchers in the field of moral philosophy: Why should I be moral? It becomes apparent that humanism does not offer a sufficient basis for resolving the tension between ethical descriptivism and ethical prescriptivism.

It should also be noted that the real origin of the Golden Rule remains a mystery for philosophers, even though this expression already appears in the $17^{\text {th }}$ century. However, it only presents an analytical terminus technicus, and a historical excursion does not provide a sufficient foundation for clarifying the essence of its contents. Comparative research studies show that the Golden Rule, in its various modifications, is present in almost all cultures, religious systems and social and economic formulations. Therefore, it is rightfully part of our common world heritage. The Golden Rule of morality thus becomes a pointer, a thread leading us to a deeper understanding of man and the world. The essence of morality does not necessarily lie in the fact that it is a social or cultural construct. On the contrary, it has its own objective basis in society which man cannot name, analyse or describe in a final way.

\section{The Judaeo-Christian perspective}

In general, it is believed that the Judaeo-Christian concept of ethics is built on the principle of love, as Jesus Christ formulated his teaching about relationships among people by the wellknown formula of love: "[L]ove your neighbour as yourself" (Matt 22,39), which he extends in a revolutionary way: "[Y]ou have heard that 'You shall love your neighbour and hate your enemies', but I say to you '[L]ove your enemies" (Matthew 22, 43-44). Here Jesus is attacking the erroneous interpretation of many rabbis; hate was not in the original Old Testament text (Roubalova, Zalec \& Kralik, 2018, pp. 51-59). This imperative is a subject of much inspiration but also misunderstanding. For example, if we compare the Muslim concept of the term "brother" with the Judaeo-Christian concept of "neighbour", we discover a diametric difference in the inclusion. While in Islam, the ethics of solidarity and empathy is focused exclusively on the community of believers, Judaeo-Christian ethics explicitly exceeds the framework of the community. The imperative of love is of a universal character, and surprisingly, it also aims at those who adopt hostile attitudes. Such an imperative has 
inspired a number of major thinkers, politicians and opinion-formers. The most famous are Leo Tolstoy, Mahatma Gandhi, Mother Teresa, Father Damien, Albert Schweitzer and others, who lived and also taught the ethics of love as a non-violent way of life (Pojman \& Vaughn, 2013, p. 628).

A critical analysis of non-violence, however, shows some serious problems that become obvious particularly in situations where there is a conflict of interests. Life is a phenomenon of a high degree of complexity, in which it is not possible to apply the principle of love in a naïve or romantic way so that all the involved parties would be satisfied. For example, what should we do when there are some people in need but we cannot help everybody as we have the means available to help only one of them? Another problem of the rule of love arises when we ask ourselves a question whether we should love our enemies at any time and under any circumstances? Should Holocaust survivors love Adolf Hitler? Should the relatives of the victims of the 9/11 terrorist attacks love Osama bin Laden? It is obvious that the principle of love must not be taken out of context and its appropriate application is subject to a deeper understanding of the meaning of love, and of the intent of God. We must not take personal revenge but let the Law take its course.

An important moment is the fact that Jesus Christ, based on the understanding of the Torah, formulated the Golden Rule in a positive way: "[S]o whatever you wish that men would do to you, do so to them; for this is in accordance with the law and the prophets" (Matthew 7,12). Thereby, he referred to the content emphasis of the texts of the Old Testament which address the principal relation to foreigners, health and the socially handicapped, and neighbours in various social, public and legal, and religious contexts (Leviticus 19). He teaches and preaches such a positive version in spite of the fact that the texts of the Torah are formulated in a negative form: do not oppress, do not steal, do not take revenge, do not bear [a grudge] etc. Typical of the rabbinical way of thinking is that a majority of ethical accents are given in pairs: You shall not ... + You shall... In making a more detailed analysis of the texts, we cannot miss the fact that a larger textual unit - the key part of the chapter (Leviticus 19,13-18) - is framed in a similar way. It starts negatively "[Y]ou shall not oppress your neighbour...", and ends positively, "...but you shall love your neighbour as yourself; I am the Lord". Jesus' positive formulation is an important indicative of thinking of life in ethical categories.

It is apparent that the negative and positive forms of the Golden Rule do not stand in a symmetrical relation. Each of them refers to another aspect of human thinking, feeling and perception of reality. Nevertheless, both of them are directed to a common point: "I am the Lord." Does this final clause have any deeper philosophical reasoning, and finally, also ethical consequences? From the philosophical point of view, it is possible to speak about a meta-ethical perspective, in which transcendental reality must be implemented in our reflections on the essence of morality, and in our search for valid responses to current ethical challenges.

The negative forms clearly reflect an attitude of passivity. The attitude "I shall not" hides a defensive posture. My "non-acting" is motivated by a kind of protection of "my" world, priorities, values, cultural preferences etc. The basis is "my" understanding of the world, "my" values, "my" preferences... that I want to indirectly protect by doing nothing to others that I myself would not like. The negative form does not lead us to such questions as: "[W]hat does my partner/my friend/my neighbour want? And what do my colleagues want?... And my church community?... etc. On the contrary, it is the positive form of the moral rule that obliges an individual to actively listen, to be empathic, to be interested in his surroundings, and to try to understand others. The formulation "Do/Act" opens content dimensions of imperatives that should guarantee moral conduct for the benefit of everybody. But is it really so? 


\section{Critical reflections}

The first major problem is the interpretation of the Golden Rule from the point of view of the context, whereby the decisive importance lies in the fact that we live in various contexts. Conduct considered morally acceptable in one culture (e. g. polygamy in Islam) is considered immoral and illegal in another culture (e. g. European). Application of the Golden Rule of morality, therefore, goes against the borderlines that cannot be satisfyingly overcome by its negative or positive formulations. As a matter of fact, both formulations may have two different meanings in two different contexts. It concerns situations where moral attitudes valid on opposite sides of the borders are not tolerable to each other. In such cases, we will not make do with an egoistic-altruistic view of moral foundations and practice.

The other problem has been already pointed out by Immanuel Kant. The core of his argument refers to a different situation position in viewing the application rule. It is a situation where a convicted criminal asks the judge for acquittal based on this rule, arguing that the judge would certainly not want anybody to send him to jail; therefore, he should not do this to others (Kant, 2017, pp. 38-44). The positive and negative forms of the Rule have their places in seeking moral answers to questions raised by life. They open a space for virtues of man, for love and forgiveness, for altruism and an active interest in others, even though the Rule does not necessarily automatically bring society the positive side of morality.

A special problem arises when the rule is to be applied at the moment of reactions between people professing different values. What if it is a fanatic that does not care about life? In such a case, the Golden Rule may open a moral space for him to kill dozens of people on his suicide mission, with a clear conscience. People have different fancies, different ideas of what is right and desirable. What if somebody likes loud rock-music? Should that person also play it loudly to his neighbours every day, being convinced of the correctness of such an attitude? Here we are tackling the issue of self-reference, which is not the ultimate measure of assessment of moral categories and ethical judgments. A moral rule in dirty hands can easily become a dangerous tool of the legalization of immoral practices. A good example is a fare dodger on public transport, or an EU member state benefiting from its EU membership but refusing to share common financial commitments.

According to Karl Popper, the Golden Rule is a good standard that can be further improved by treating other people the way they want to be treated, wherever possible (Dupré, 2013 , p. 78). But the problem is how to know what other people want? How can we know that they correctly understand themselves, and that they correctly understand the world? The situation is complicated by the semantic and procedural aspects of the communication. How can we be sure that they correctly express their wishes and that we correctly understand them? And the last objection of the Popperian view is that in this case it is not a moral rule, but a description of a mechanism by which people make decisions in their actions. The selfregulation dimension of the Golden Rule is thus substantially reduced, and ceases to be a principle which not only provides prescriptive horizons of ethics but also reveals the substance of the moral conduct of man. The Golden Rule becomes a pointer to the existence of an ethical entity in the light of which both, the positive and negative interpretations acquire a coherent meaning of mutual relation.

Finally, the last problem is connected with the fact that nobody is an ideal observer who could, from a neutral point, observe the moral weight of a particular component entering the dialectics of the Golden Rule. Kalajtzidis, in his optimistic reflections on the ethics of social implications and his call for objectively valid and unconditional principles, deals with the relativity of ethical standards and categories that pose a serious problem for the normative ambitions of any ethical theory: "[T] which accepts them and not in others. As a result, it is impossible to evaluate other societies 
other than those which accept them" (Kalajtzidis, 2013, p. 170). It is an objective reality that everybody has some prejudices, their own values and cultural preferences, or limitations in communication with their environment (Berger \& Luckmann, 1996, pp. 162-165). Expertise in the field of ethics, based on the moral quality of intentions and the social consequences of the actions, similarly encounter the question of the point of reference, in which the nature of the intention and the effect of the consequences of a im/moral act will be judged, therefore, the search for universal values and moral models remains open (Gluchman, 2017, p. 62). It can be said, I believe, that nobody can, therefore, impose any absolute moral judgements of definitive validity on anybody, not even on themselves. Neither can man's conscience be such an observer, as it is not absolute; on the contrary, it is a phenomenon which is culturally, religiously and sociologically conditioned.

\section{Conclusion}

The question whether moral categories fall within the world of relative phenomena or whether they have their own absolute coordinates remains unanswered from the humanist point of view, even though this question is currently extremely relevant and more urgent than ever before. The current relativism in ethics and philosophy faces the issue of consistency. It seems that a deeper understanding of the current ethical challenges needs to be guided in terms of such transcendent realm, where both, the negative and the positive formulations of morality point to a unifying metaphysical reality behind our reasoning. This position, however, correlates with those cognitivist and realist scholars that support the Divine Command theory. In such a case we could claim that the Golden Rule of morality under some conditions ceases to be a rule, and becomes an intrinsic question. A kind of indicator of the limitations of man's knowledge, confirmation of an existential necessity to know and discover moral frameworks, and to seek such ethical solutions to particular situations that transcend man.

\section{Acknowledgement}

This submission was created as part of a research assignment for the KEGA 044UKF-4/2016 grant Nanoethics - education tools formation: e-book and web platform.

\section{References}

BERGER, P. L. \& LUCKMANN, T. (1996): The Social Construction of Reality. New York: Penguin Books.

BLACKBURN, S. (2013): Ethics: A Very Short Introduction. Oxford: Oxford University Press.

DUPRÉ, B. (2013): 50 Philosophy Ideas You Really Need to Know. New York: Quercus. EPSTEIN, G. M. (2010): Good Without God: What a Billion Non-religious People Do Believe. New York: Harper Collins Publishers.

FIRMINGER, T. (2008): Pahlavi Texts of Zoroastrianism, Part 2 of 5: The Dadistan-i Dinik and the Epistles of Manuskihar, trans. E. W. West. Oxford: Clarendon \& Oxford University Press.

GANGULY, K. M. (2017): Mahabharata Anusana Parva, [online] [Retrieved December 15, 2017].

Available at: http://www.mahabharataonline.com/translation/mahabharata_13b078.php.

GLUCHMAN, V. (2017): G. E. Moore and theory of moral/right action in ethics of social consequences. In: Ethics \& Bioethics (in Central Europe), 2017, 7(1-2), pp. 57-65.

CHILTON, B. D. \& NEUSNER, J. (2008): The Golden Rule: The Ethics of Reciprocity in World Religions. London \& New York: Continuum. 
JASNOW, R. (1992): A Late Period Hieratic Wisdom Text (P. Brooklyn 47.218.135). Chicago: The Oriental Institute.

KALAJTZIDIS, J. (2013): Ethics of social consequences as a contemporary consequentialist theory. In: Ethics \& Bioethics (in Central Europe), 3(3-4), pp. 159-171.

KANT, I. (2017): Groundwork of the Metaphysics of Morals, trans. T. K. Abbott. Digireads.com Publishing.

LEE, A. \& MUSINGS, E. (2013): A Decalogue for the Modern World, [online] [Retrieved December 10, 2018]. Available at: http://www.patheos.com/blogs/daylightatheism/ essays/the-new-ten-commandments/.

LEGGE, J. (2017): Chinese Text Project, ed. D. Sturgeon, [online] [Retrieved November 20, 2018]. Available at: http://ctext.org/analects/wei-ling-gong.

NEUSNER, J. \& CHILTON, B. (2008): The Golden Rule - Analytical Perspectives. Lanham: University Press of America.

POJMAN, L. P. \& VAUGHN, L. (2013): The Moral Life: An Introductory Reader in Ethics and Literature. Oxford: Oxford University Press.

RHYS-DAVIDS, T. W. (1904): Gautama Buddha (B.C. 623-543). In: E. Singleton (ed.): The World's Great Events in Five Volumes: A History of the World from Ancient to Modern Times, B. C. 4004 to A. D. 1903. New York: P. F. Collier \& Son, pp. 124-135.

ROUBALOVA, M., ZALEC, B. \& KRALIK, R. (2018): Meaning, Necessity, and Value of Obedience According to the Sidra "Lech-lech" in rabbinical tradition. In: XLinguae, 11(2), pp. 51-59.

TAVILLA, I., KRALIK, R. \& MARTIN, J. G. (2018): A brief recollection of Kierkegaard's testimony on Reformation 500th anniversary. In: XLinguae, 11(1), pp. 354-362.

WATTLES, J. (1996): The Golden Rule. Oxford: Oxford University Press. 